\title{
Viability of glioblastoma stem cells is effectively reduced by diisothiocyanate-derived mercapturic acids
}

\author{
KAMILA CWIKLOWSKA ${ }^{1}$, MIKE-ANDREW WESTHOFF ${ }^{2}$, SIMON FREISINGER ${ }^{2}$, ANNIKA DWUCET ${ }^{1}$, \\ MARC-ERIC HALATSCH ${ }^{1}$, UWE KNIPPSCHILD ${ }^{3}$, KLAUS-MICHAEL DEBATIN ${ }^{2}$, REINHOLD SCHIRMBECK ${ }^{4}$, \\ LUKASZ WINIARSKI $^{5}$, JOZEF OLEKSYSZYN ${ }^{5}$, CHRISTIAN RAINER WIRTZ ${ }^{1}$ and TIMO BURSTER ${ }^{1}$ \\ ${ }^{1}$ Department of Neurosurgery, Surgery Center; ${ }^{2}$ Department of Pediatrics and Adolescent Medicine; \\ ${ }^{3}$ Department of General and Visceral Surgery, Surgery Center; ${ }^{4}$ Internal Medicine I, Ulm University Medical Center, \\ D-89081 Ulm, Germany; ${ }^{5}$ Faculty of Chemistry, Wroclaw University of Technology, 50-370 Wroclaw, Poland
}

Received October 6, 2016; Accepted February 1, 2017

DOI: $10.3892 / \mathrm{ol} .2018 .9347$

\begin{abstract}
Glioblastoma is the most aggressive tumor of the central nervous system and is manifested by diffuse invasion of glioblastoma stem cells into the healthy tissue, chemoresistance and recurrence. Despite aggressive therapy, consisting of maximal surgical resection, radiotherapy and chemotherapy with temozolomide $\left(\mathrm{Temodal}^{\circledR}\right)$, life expectancy of patients with glioblastoma is typically less than 15 months. In general, natural isothiocyanates isolated from plants of the Cruciferae family are selectively cytotoxic to tumor cells. It has been demonstrated previously that diisothiocyanate-derived mercapturic acids are highly cytotoxic to colon cancer cells. In the present study, the application of diisothiocyanate-derived mercapturic acids led to a decrease in the viability of an established glioblastoma cell line, primary patient-derived sphere-cultured stem cell-enriched cell populations (SCs), and cells differentiated from SCs. Consequently, targeting glioblastoma cells by diisothiocyanate-derived mercapturic acids is a promising approach to restrict tumor cell growth and may be a novel therapeutic intervention for the treatment of glioblastoma.
\end{abstract}

\section{Introduction}

A major drawback of cancer cell therapy is chemoresistance of cancer stem cells, resulting in repopulation of the tumor

Correspondence to: Dr Timo Burster, Department of Neurosurgery, Surgery Center, Ulm University Medical Center, AlbertEinstein-Allee 23, D-89081 Ulm, Germany

E-mail: timo.burster@uni-ulm.de

Abbreviations: ITCs, isothiocyanates; PCs, SC-derived differentiated/adherent glioblastoma cells; PBMCs, peripheral blood mononuclear cells; ROS, reactive oxygen species; SCs, sphere-cultured stem cell-enriched glioblastoma cell populations; TMZ, temozolomide

Key words: glioblastoma, isothiocyanates, MTT, diisothiocyanates, glioblastoma stem cells niche even following a period of prolonged dormancy. Glioblastoma stem cells are responsible for the maintenance and phenotype of glioblastoma (astrocytoma grade IV or glioblastoma multiforme), the most common and aggressive tumor of the central nervous system, which is characterized by rapid cell proliferation and diffuse invasion into the healthy tissue (1). Following surgery, radiation and chemotherapy, the prognosis for patients diagnosed with glioblastoma remains poor. For instance, the postoperative median survival time of patients with glioblastoma is 6 months; radiotherapy increases the survival time of patients to 12 months, and radiotherapy in combination with the standard chemotherapeutic agent temozolomide $\left(\mathrm{TMZ}\right.$; Temodal ${ }^{\circledR}$ ) increases the survival time by a further 2.6 months (total, 14.6 months) (2). Therefore, the elucidation of novel and more effective chemotherapeutics that interfere with glioblastoma stem cell proliferation, particularly invasion, is required.

Isothiocyanates (ITCs) are natural components of the Cruciferae family of plants (which includes radish, broccoli or mustard) that have intrinsic antitumor capacity as previously demonstrated $(3,4)$. A major advantage of ITCs is that they selectively elicit an accumulation of reactive oxygen species (ROS), leading to apoptosis in transformed cells in contrast with wild-type cells, which are more resistant to ROS (5). Recently, Grzywa et al (6) observed that the application of diisothiocyanate-derived mercapturic acids was cytotoxic to a human adenocarcinoma cell line with a drug concentration yielding half-maximal response $\left(\mathrm{EC}_{50}\right)$ of $2.02 \mu \mathrm{M}$. On the basis of these data, in the present study, various diisothiocyanate-derived mercapturic acids (J1-J4; Fig. 1) were investigated, and it was identified that J1-J4 selectively inhibited cell viability in glioblastoma cells and glioblastoma stem cells, indicating that these components are promising antitumor drugs in glioblastoma research.

\section{Materials and methods}

Diisothiocyanate-derived mercapturic acids. Diisothiocyanate-derived mercapturic acids were synthesized as described previously (6). The diisothiocyanates (for compounds J3 and J4) were prepared from appropriate 
diamine (Sigma-Aldrich; Merck KGaA, Darmstadt, Germany) and carbon disulfide (Sigma-Aldrich; Merck KGaA) using 2-(1H-benzotriazol-1-yl)-1,1,3,3-tetramethyluronium hexafluorophosphate (Iris Biotech GmbH, Marktredwitz, Germany) in the presence of triethylamine (Avantor Performance Materials Poland S.A., Gliwice, Poland). The diisothiocyanates (for compounds $\mathrm{J} 1$ and $\mathrm{J} 2$ commercially available from Sigma-Aldrich; Merck KGaA) and $N$-acetyl-L-cysteine (Sigma-Aldrich; Merck KGaA) were mixed with sodium hydrogen carbonate (Avantor Performance Materials Poland S.A.) to yield the final product (diisothiocyanate-derived mercapturic acid).

Peripheral blood mononuclear cells (PBMCs). Following Ficoll isolation of human PBMCs from heparinized blood (buffy coat), PBMCs were resuspended in Roswell Park Memorial Institute (RPMI-1,640 medium; Thermo Fisher Scientific, Inc., Waltham, MA, USA) containing $1.5 \%$ fetal bovine serum (FBS; Thermo Fisher Scientific, Inc.) and 1\% penicillin $(120 \mathrm{mg} / \mathrm{ml}) /$ streptomycin $(120 \mathrm{mg} / \mathrm{ml}$; Thermo Fisher Scientific, Inc.), and were cultured with J1-J4, TMZ or dimethylsulfoxide (DMSO) for $72 \mathrm{~h}$ at $37^{\circ} \mathrm{C}$ and $5 \% \mathrm{CO}_{2}$. The use of PBMCs for in vitro studies was approved by the local Ethics committee of Ulm University, Ulm, Germany (no. 327/14).

Glioblastoma cell line. The human glioblastoma cell line U87-MG (U87) (American Type Culture Collection, Manassas, VA, USA), was cultured in Dulbecco's modified Eagle's medium (DMEM; Thermo Fisher Scientific, Inc.) supplemented with $10 \% \mathrm{FBS}$ and $1 \%$ penicillin $(120 \mathrm{mg} / \mathrm{ml})$ /streptomycin $(120 \mathrm{mg} / \mathrm{ml})$ at $37^{\circ} \mathrm{C}$ in a $5 \% \mathrm{CO}_{2}$ atmosphere.

Sphere-cultured stem cell-enriched glioblastoma cell populations (SCs). Astrocytoma grade IV tissue from 3 patients was obtained during surgery at the hospital in Ulm University Medical Center in Günzburg, Germany [nos. 35 (44 years, male; sample collected August 2009), 38 (75 years, male; sample collected, July 2010), and 40 (57 years, female; sample collected, July 2010)] was minced separately, washed in PBS and incubated with TrypLE ${ }^{\mathrm{TM}}$ Express (Gibco; Thermo Fisher Scientific, Inc.). Cells were filtered and cultured at $37^{\circ} \mathrm{C}$ in a $5 \% \mathrm{CO}_{2}$ atmosphere in DMEM/Ham's F-12 medium (Gibco; Thermo Fisher Scientific, Inc.) containing L-glutamine, $0.01 \%$ (v/v) epidermal growth factor (EGF; Biomol GmbH, Hamburg, Germany), $0.04 \%$ (v/v) fibroblast growth factor (FGF; Miltenyi Biotec GmbH, Bergisch Gladbach, Germany), 1\% (v/v) B27 (Gibco; Thermo Fisher Scientific, Inc.), 2\% fungizone (Gibco; Thermo Fisher Scientific, Inc.) and $1 \%$ penicillin $(120 \mathrm{mg} / \mathrm{ml})$ /streptomycin (120 mg/ml; Thermo Fisher Scientific, Inc.) (7). These cells were defined as sphere-cultured stem cell-enriched glioblastoma cell populations (SCs; identified as SC35, SC38 and SC40 according to the patient number from which they derived). Stem cell and differentiation markers were expressed accordingly (8). To obtain adherent glioblastoma cells (PCs; identified as PC35, PC38 and PC40 according to the patient number from which they derived), SCs were kept at $37^{\circ} \mathrm{C}$ (5\% $\mathrm{CO}_{2}$ atmosphere) in DMEM supplemented with $10 \%$ FBS with $2 \mathrm{mM}$ glutamine and $1 \%$ penicillin/streptomycin (120 mg/ml each; Thermo Fisher Scientific, Inc.) as SCs differentiate into PCs when FBS is present in the culture medium. Use of SCs and patient samples was approved by the local ethics committee of Ulm University (\#162/10).

Determination of cellular metabolic activity (cell viability). An MTT test was performed to assay the metabolic activity of the indicated cell populations as a measure of cell viability. The method is based on the reduction of the yellow tetrazolium compound MTT by metabolically active cells to an intracellular purple formazan, which is spectrophotometrically quantified. Adherent glioblastoma cells (U87, PC35, PC38 or PC40) were seeded in 96-well flat-bottomed tissue culture plates at $1.5 \times 10^{4}$ cells $/ \mathrm{ml}$ in $100 \mu 1$ DMEM containing $10 \% \mathrm{FBS}$ and $1 \%$ penicillin/streptomycin. SCs (SC35, SC38 or SC40) were seeded in 96-well flat-bottomed tissue culture plates at $1.5 \times 10^{4}$ cells $/ \mathrm{ml}$ in $90 \mu \mathrm{l}$ DMEM/Ham's F-12 containing $0.01 \% \mathrm{EGF}, 0.04 \% \mathrm{FGF}, 1 \% \mathrm{~B} 27,2 \%$ fungizone and $1 \%$ penicillin/streptomycin. Freshly isolated PBMCs were seeded in 96-well flat-bottomed tissue culture plates at $5 \times 10^{6}$ cells/ml in $90 \mu 1$ RPMI-1,640 medium containing $10 \%$ FBS, $1 \%$ penicillin/streptomycin, but lacking L-glutamine and phenol red. After $24 \mathrm{~h}$ of incubation, the medium was removed. Various concentrations $(0.01,0.1,1,10$ and $100 \mu \mathrm{M})$ of J1, J2, J3, J4 or TMZ (DMSO served as a control) were prepared in DMEM containing $1.5 \% \mathrm{FBS}$ and $1 \%$ penicillin/streptomycin, and added to U87, PC35, PC38 and PC40 cells (final volume, $100 \mu \mathrm{l}$ ); in the case of SCs or PBMCs, the medium was unchanged and the $\mathrm{J} 1, \mathrm{~J} 2, \mathrm{~J} 3, \mathrm{~J} 4$ or TMZ was added directly (final volume, $100 \mu \mathrm{l}$ ). The cells were cultured for a further 3 days prior to removal of the medium. U87, PC35, PC38 and PC40 cells were incubated with $100 \mu 1$ MTT working solution (Sigma-Aldrich; Merck KGaA), diluted 1:5 in RPMI-1640 medium without L-glutamine and phenol red. SC plates were centrifuged for $390 \times \mathrm{g}$ for $5 \mathrm{~min}$ at room temperature, the supernatant was removed, and cells were resuspended in $100 \mu \mathrm{l}$ MTT working solution; $25 \mu \mathrm{l}$ MTT working solution was added directly to PBMCs. Cells were incubated for $3 \mathrm{~h}$ at $37^{\circ} \mathrm{C}$. Following incubation, formazan crystals were solubilized with $100 \mu \mathrm{l}$ propan-2-ol. Cell viability was determined by measuring the optical density at $550 \mathrm{~nm}$ using a microplate spectrometer (Tecan Spectra Classic, Tecan Group Ltd., Männedorf, Switzerland).

Microscopy images. Images were captured using a PrimoVert microscope and AxioCam ICc1 camera (Zeiss AG, Oberkochen, Germany).

Analysis of DNA content. U87 cells were incubated with J1, J2, $\mathrm{J} 3$, J4 or TMZ, or a combination of TMZ with $\mathrm{J} 1, \mathrm{~J} 2, \mathrm{~J} 3$ or J4 for $144 \mathrm{~h}$ at $37^{\circ} \mathrm{C}\left(\mathrm{J} 1-\mathrm{J} 4\right.$ were used at their $\mathrm{EC}_{50}$ values of $\mathrm{J} 1$, $250 \mathrm{nM}$; J2, 290 nM; J3, 2200 nM; J4, 500 nM; TMZ was used at $100 \mu \mathrm{M})$. The cell death readout used was DNA fragmentation (sub- $\mathrm{G}_{1}$ population), a hallmark of apoptosis, as assessed by fluorescence-activated cell sorting using a FACScan instrument and CellQuest software 5.1 (BD Biosciences, Franklin Lakes, NJ, USA) analysis of DNA fragmentation of propidium iodide-stained nuclei as previously described (9). The specific (induced) DNA fragmentation was calculated as follows: 100x [experimental DNA fragmentation (\%)-spontaneous DNA fragmentation (\%)]/[100\%-spontaneous DNA fragmentation 


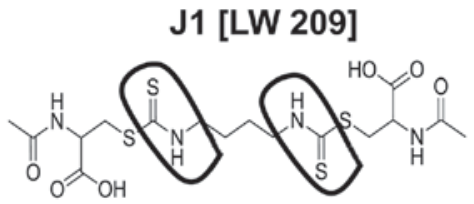

J3 [AR 11.2 NAC]

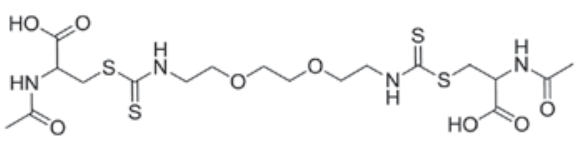

\section{J2 [LW 216]}

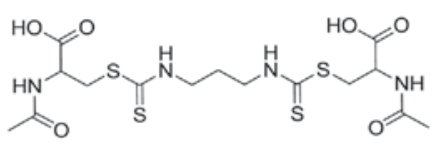

J4 [AR 16.2.1 NAC]

Figure 1. Chemical structures of diisothiocyanate-derived mercapturic acids. The diisothiocyanate structure is indicated in J1 by the thick line rings. AR, Agata Rudnicka; LW, Lukasz Winiarski; NAC, N-Acetyl-L-cysteine.

(\%)]. For cell cycle distribution of live cells, only populations in clearly identifiable phases of the cell cycle, i.e., $\mathrm{G}_{0 / 1^{-}}, \mathrm{S}-$ or $\mathrm{G}_{2} / \mathrm{M}$-phase, were considered. For analysis of polyploidy, cells with DNA content exceeding that observed in the $G_{2} / M$-phase were compared with the total cell numbers obtained from the cell cycle analysis. For each analysis, $\sim 10,000$ cells were assayed.

Alterations in cell number. U87 cells were seeded and allowed to proliferate with or without J1, J2, J3, J4 or TMZ for the indicated times, prior to treatment with a trypsin/EDTA solution (Biochrom GmbH, Berlin, Germany) to suspend cells. The cell suspension was diluted 1:100 in CASYton solution (Innovatis AG, Reutlingen, Germany) and cell numbers were determined using a $\mathrm{CASY}^{\circledR} 1 \mathrm{DT}$ cell counter (Innovatis AG).

Statistical analysis. Results are presented as the mean \pm standard error of the mean. Statistical analysis was assessed using an unpaired two-tailed Student's t-test and $\mathrm{EC}_{50}$ values were calculated using Prism (version 6; GraphPad Software, Inc., La Jolla, CA, USA).

\section{Results and Discussion}

Diisothiocyanate-derived mercapturic acids are cytotoxic to the glioblastoma cell line (U87). To be viable for treatment of glioblastoma, diisothiocyanate-derived mercapturic acids in glioblastoma treatment are required to be able to traverse the blood-brain barrier (BBB). Therefore, compounds J1-J4 (Fig. 1) (6) were analyzed using online BBB Predictor software admetSAR (1mmd.ecust.edu.cn:8000) (10). J1-J4 were identified to be theoretically able to cross the BBB, making delivery of such diisothiocyanate-derived mercapturic acids to the site of requirement possible.

It was determined whether diisothiocyanate-derived mercapturic acids are a potential therapeutic option for treatment of glioblastoma. U87 cells were incubated with various concentrations of $\mathrm{J} 1, \mathrm{~J} 2, \mathrm{~J} 3, \mathrm{~J} 4$ or TMZ, and the metabolic activity of U87 cells was determined using an MTT assay. $\mathrm{J} 1$ and $\mathrm{J} 2$ were identified to markedly decreased U87 cell viability at a final concentration of $1 \mu \mathrm{M}$ with comparatively low $\mathrm{EC}_{50}$ values of 250 and $290 \mathrm{nM}$, respectively, in contrast with J3 (2.2 $\mu \mathrm{M})$ and J4 (500 nM) (Fig. 2). At $<1 \mu \mathrm{M} \mathrm{J} 1, \mathrm{~J} 2, \mathrm{~J} 3$ or $\mathrm{J} 4$, there was no marked effect on PBMCs freshly isolated from peripheral blood, and the $\mathrm{EC}_{50}$ values were $\sim 10$-fold higher than for U87 cells. Furthermore, U87 cells exhibited alterations in morphology when treated with $\mathrm{J} 1, \mathrm{~J} 2, \mathrm{~J} 3$ or $\mathrm{J} 4$; in particular, $\mathrm{J} 1$ and $\mathrm{J} 2$ caused alterations in the size and cell density of U87 cells at a final concentration of as low as $0.01 \mu \mathrm{M}$ (Fig. 3, microscopic images). Notably, the high concentration of TMZ used did not elicit a decrease in cell viability of $<50 \%$, i.e., U87 cells exhibit increased sensitivity to diisothiocyanate-derived mercapturic acids than to the chemotherapeutic agent TMZ.

Furthermore, it was assessed whether $\mathrm{EC}_{50}$ values of $\mathrm{J} 1$ $(250 \mathrm{nM}), \mathrm{J} 2(290 \mathrm{nM}), \mathrm{J} 3(2.2 \mu \mathrm{M})$ or J4 (500 nM), or the combination with TMZ $(100 \mu \mathrm{M})$ were able to induce apoptosis in U87 cells by investigating the cell cycle distribution. Treatment with relatively low concentrations of diisothiocyanate-derived mercapturic acids caused a significantly prolonged negative effect on cell numbers for J1, J2 and J3 (Fig. 4A). Although only limited induction of apoptosis was observed upon single treatment with $\mathrm{J} 1, \mathrm{~J} 2, \mathrm{~J} 3$ or $\mathrm{J} 4$, it is noteworthy that robust cell death induced by TMZ, the standard chemotherapeutic agent used to treat glioblastoma, was dependent on high concentrations of the drug (Fig. 4B; see also Fig. 2). Furthermore, single treatment with $\mathrm{J} 1, \mathrm{~J} 2, \mathrm{~J} 3$ or $\mathrm{J} 4$ affects the cell cycle distribution and the nuclear integrity of U87 cells (Fig. 4C and D), possibly indicating that the cell cycle distribution of U87 cells is altered by $\mathrm{J} 1$. These results demonstrate that diisothiocyanate-derived mercapturic acids are cytotoxic to the glioblastoma cell line U87.

Viability of glioblastoma stem cells is decreased by diisothiocyanate-derived mercapturic acids. Further experiments were performed to address the question of whether the viability of primary patient-derived glioblastoma stem cells or primary glioblastoma cells is susceptible to diisothiocyanate-derived mercapturic acids. To this end, SCs from 3 different glioblastoma patients (SC35, SC38 and SC40) or SCs differentiated using FBS (PCs; PC35, PC38 and PC40) were incubated with $\mathrm{J} 1, \mathrm{~J} 2, \mathrm{~J} 3$ or $\mathrm{J} 4$, and cell viability was measured using an MTT assay. The cell viability of SCs or PCs was gradually decreased by increasing the concentration of $\mathrm{J} 1, \mathrm{~J} 2, \mathrm{~J} 3$ or J4 (Figs. 5 and 6). These compounds at a concentration of $1 \mu \mathrm{M}$ decreased the cell viability of PCs markedly in contrast with SCs which exhibited decreases in cell viability of $50 \%$ following treatment with $\mathrm{J} 1, \mathrm{~J} 2$, J3 or J4 which may be due 

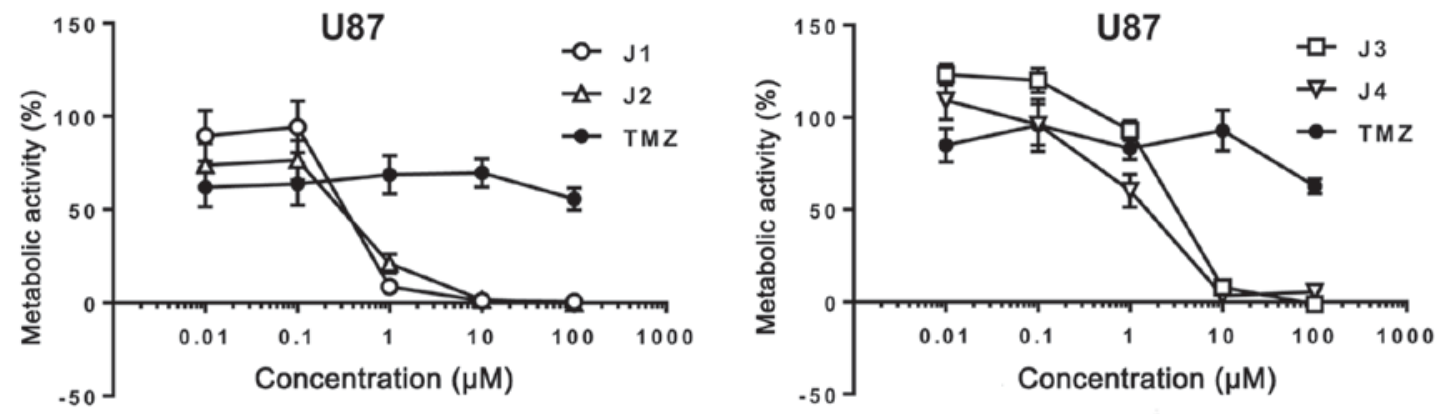

\begin{tabular}{|c|c|c|}
\hline Compound & $\begin{array}{c}\mathrm{EC}_{50}(\mu \mathrm{M}) \\
\text { U87 }\end{array}$ & $\begin{array}{c}\mathrm{EC}_{50}(\mu \mathrm{M}) \\
\mathrm{PBMCs}\end{array}$ \\
\hline J1 & 0.25 & 4.49 \\
\hline J2 & 0.29 & 6.4 \\
\hline J3 & 2.2 & 13.71 \\
\hline J4 & 0.5 & 5.57 \\
\hline
\end{tabular}

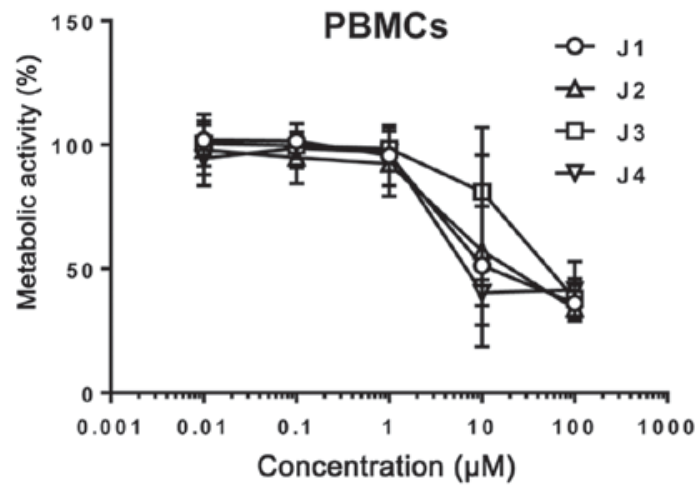

Figure 2. MTT assay to determine metabolic activity. The human glioblastoma cell line U87 or PBMCs were cultured in the presence or absence of J1, J2, J3, J4 or TMZ for $72 \mathrm{~h}$ and cell viability was measured using an MTT assay. The MTT assay was performed in triplicate with four independent experiments for U87 cells $(\mathrm{n}=4)$ and three independent experiments for PBMCs $(\mathrm{n}=3)$. PBMC, peripheral blood mononuclear cell; TMZ, temozolomide; $\mathrm{EC}_{50}$, drug concentration yielding half-maximal response.

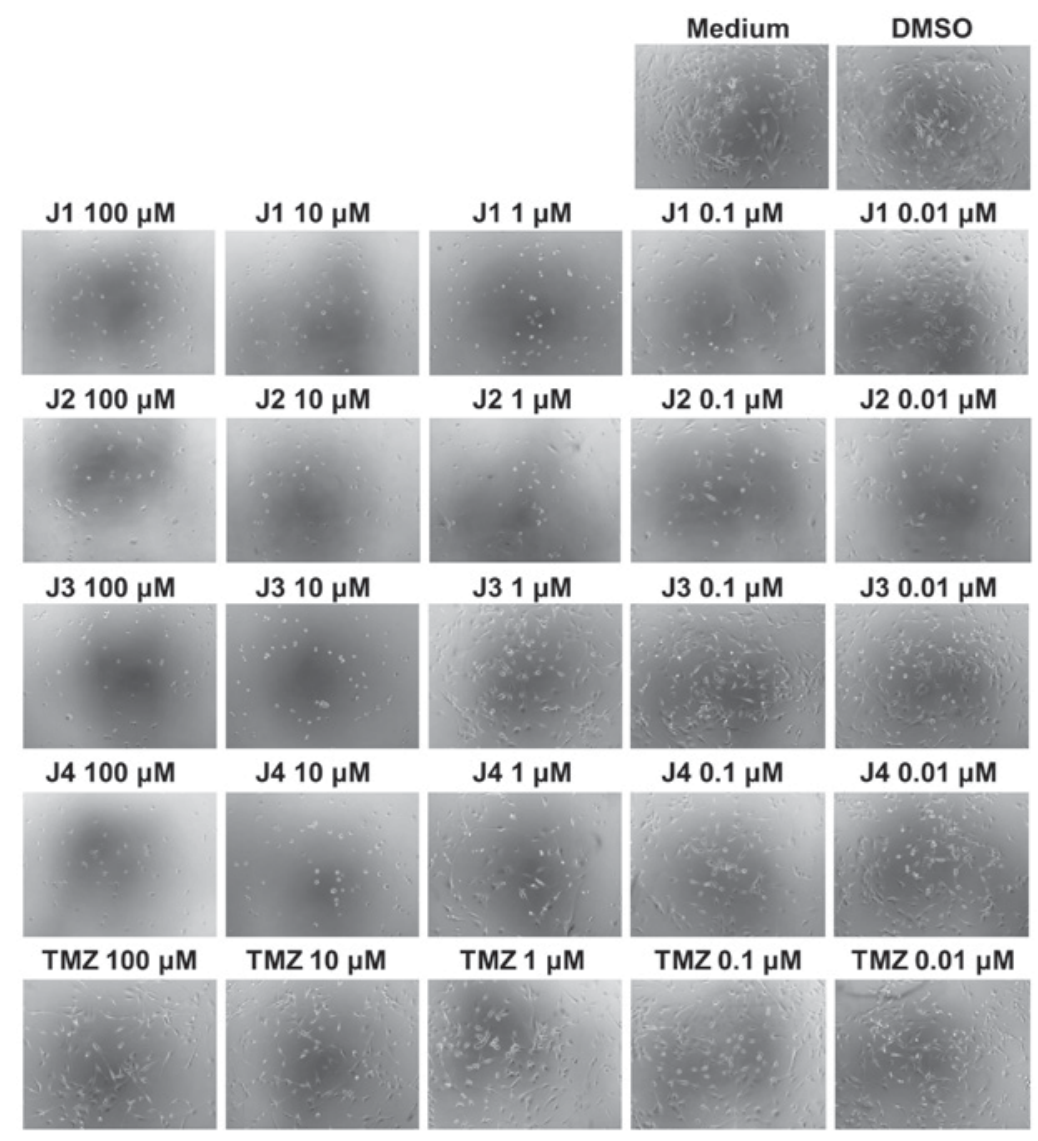

Figure 3. Microscopic images of U87 cells following treatment with medium, DMSO, J1, J2, J3, J4 or TMZ. U87 cells were treated with various concentrations of J1, J2, J3, J4 or TMZ. DMSO and medium treatments served as controls. After $72 \mathrm{~h}$, images were captured under a light microscope. Magnification, x10. DMSO, dimethylsulfoxide; TMZ, temozolomide. 
A
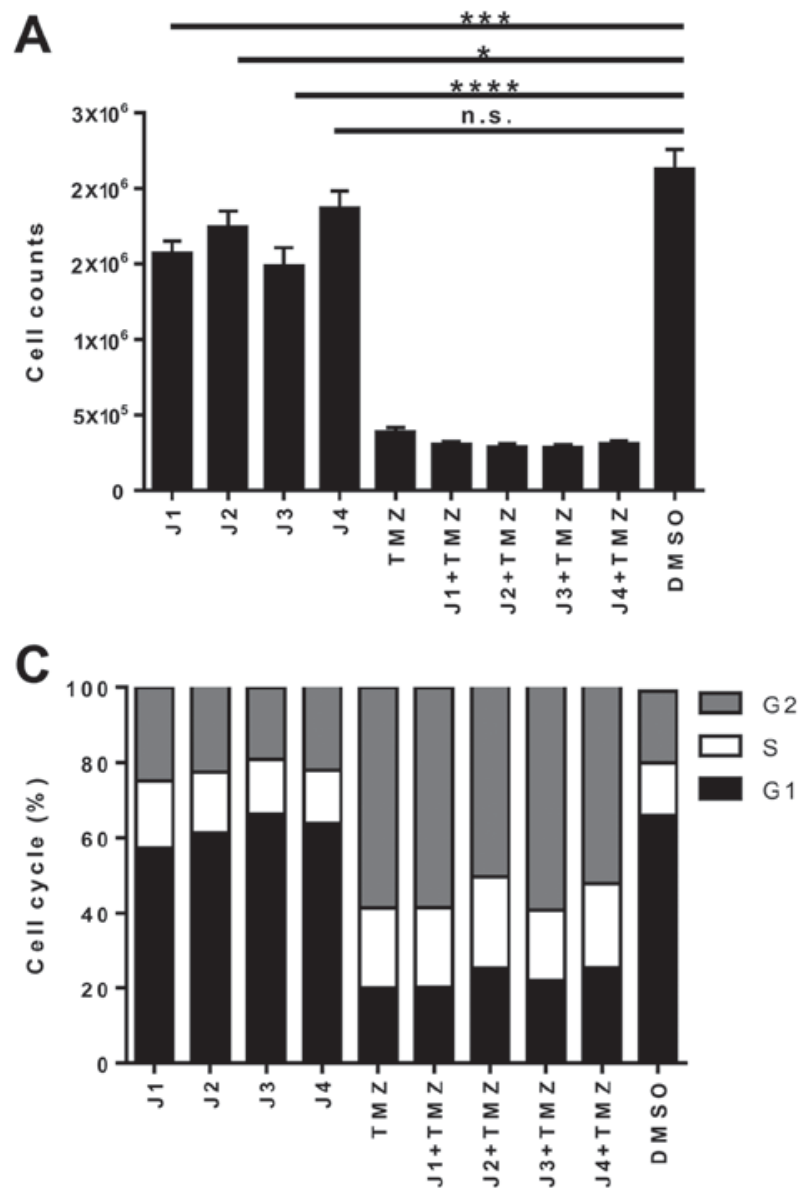

B
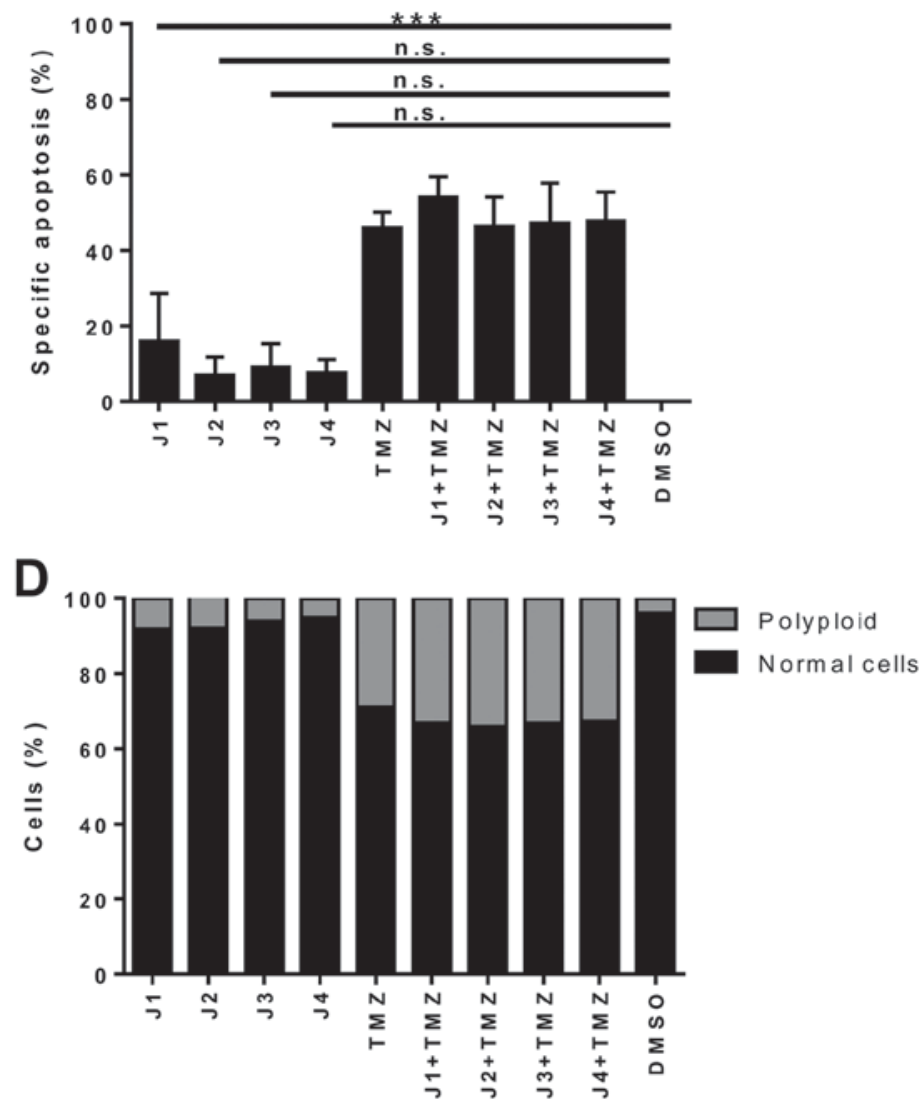

Figure 4. Apoptosis and cell distribution in U87 cells treated with J1-J4. U87 cells were incubated with J1, J2, J3, J4 or TMZ, or a combination of TMZ with $\mathrm{J} 1, \mathrm{~J} 2$, J3 or J4, for $144 \mathrm{~h}$. J1-J4 were used at their $\mathrm{EC}_{50}$ values (J1, $250 \mathrm{nM}$; J2, $290 \mathrm{nM} ; \mathrm{J} 3,2,200 \mathrm{nM}$; J4, $500 \mathrm{nM}$ ), and TMZ was used at $100 \mu \mathrm{M}$. (A) Cell numbers were determined using a CASY ${ }^{\circledR} 1$ DT cell counter. (B) DNA fragmentation, (C) cell cycle distribution of live cells, and (D) analysis of polyploidy, determined using propidium iodide staining and flow cytometry. Results are from three independent experiments. ${ }^{*} \mathrm{P} \leq 0.05 ;{ }^{* * * *} \mathrm{P} \leq 0.001 ;{ }^{* * * * *} \mathrm{P} \leq 0.0001$. n.s., not significant; TMZ, temozolomide; DMSO, dimethylsulfoxide; $\mathrm{EC}_{50}$, drug concentration yielding half-maximal response.

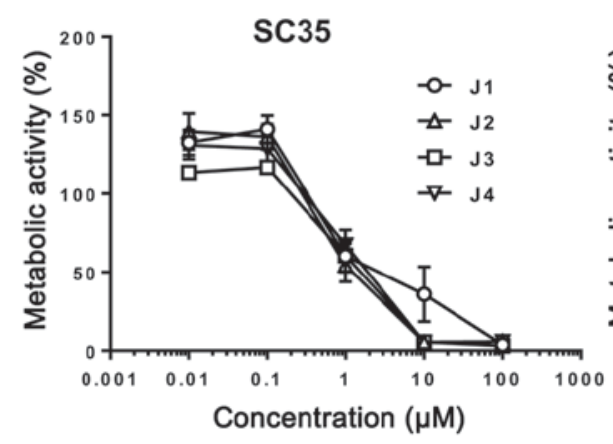

\begin{tabular}{|c|c|}
\hline $\begin{array}{c}\text { Compound } \\
\text { (SC35) }\end{array}$ & $\mathrm{EC}_{50}(\mu \mathrm{M})$ \\
\hline J1 & 2.0 \\
\hline J2 & 0.8 \\
\hline J3 & 0.8 \\
\hline J4 & 1.0 \\
\hline
\end{tabular}

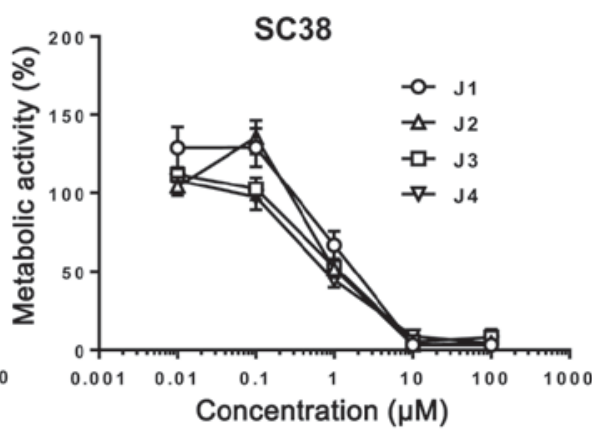

\begin{tabular}{|c|c|}
\hline $\begin{array}{c}\text { Compound } \\
\text { (SC38) }\end{array}$ & $\mathrm{EC}_{50}(\mu \mathrm{M})$ \\
\hline $\mathrm{J} 1$ & 0.7 \\
\hline J2 & 0.8 \\
\hline J3 & 1.0 \\
\hline J4 & 1.5 \\
\hline
\end{tabular}

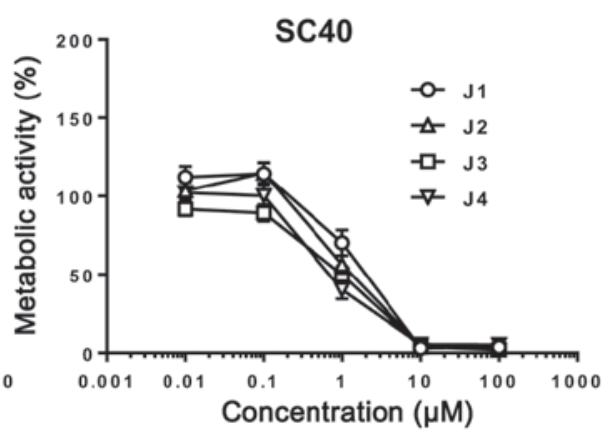

\begin{tabular}{|c|c|}
\hline $\begin{array}{c}\text { Compound } \\
\text { (SC40) }\end{array}$ & $\mathrm{EC}_{50}(\mu \mathrm{M})$ \\
\hline $\mathrm{J} 1$ & 0.5 \\
\hline $\mathrm{J} 2$ & 1.0 \\
\hline $\mathrm{J3}$ & 1.0 \\
\hline $\mathrm{J} 4$ & 1.1 \\
\hline
\end{tabular}

Figure 5. Cell viability of SCs. SC35, SC38 and SC40 cells were cultured in the presence or absence of J1, J2, J3 or J4 for $72 \mathrm{~h}$, and the metabolic activity was determined using an MTT assay. Three independent experiments were performed $(n=3)$. SC, sphere-cultured stem cell-enriched glioblastoma cell population; $\mathrm{EC}_{50}$, drug concentration yielding half-maximal response.

to distinct proliferation rates (11). Importantly, the viability of PCs and SCs may be decreased by diisothiocyanate-derived mercapturic acids; however, SCs are more resistant to diisothiocyanate-derived mercapturic acids. 

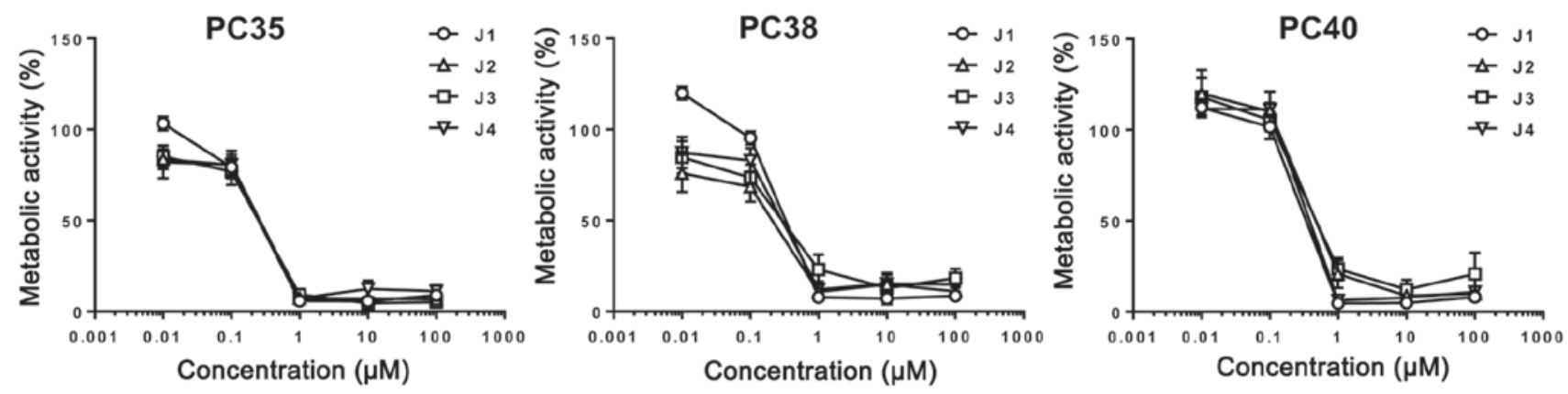

\begin{tabular}{|c|c|}
\hline $\begin{array}{c}\text { Compound } \\
\text { (PC35) }\end{array}$ & $\mathrm{EC}_{50}(\mu \mathrm{M})$ \\
\hline J1 & 0.17 \\
\hline J2 & 0.28 \\
\hline J3 & 0.3 \\
\hline J4 & 0.27 \\
\hline
\end{tabular}

\begin{tabular}{|c|c|}
\hline $\begin{array}{c}\text { Compound } \\
(\mathrm{PC} 38)\end{array}$ & $\mathrm{EC}_{50}(\mu \mathrm{M})$ \\
\hline $\mathrm{J} 1$ & 0.2 \\
\hline $\mathrm{J} 2$ & 0.22 \\
\hline $\mathrm{J} 3$ & 0.3 \\
\hline $\mathrm{J} 4$ & 0.3 \\
\hline
\end{tabular}

\begin{tabular}{|c|c|}
\hline $\begin{array}{c}\text { Compound } \\
\text { (PC40) }\end{array}$ & $\mathrm{EC}_{50}(\mu \mathrm{M})$ \\
\hline $\mathrm{J} 1$ & 0.46 \\
\hline $\mathrm{J} 2$ & 0.6 \\
\hline $\mathrm{J} 3$ & 1.4 \\
\hline $\mathrm{J} 4$ & 0.75 \\
\hline
\end{tabular}

Figure 6. Cell viability of PCs. PC35, PC38 and PC40 cells were cultured in the presence or absence of J1, J2, J3 or J4 for 72 h, and the metabolic activity was determined using an MTT assay. Three independent experiments were performed $(\mathrm{n}=3)$. PC, SC-derived differentiated primary glioblastoma cell; EC E $_{50}$, drug concentration yielding half-maximal response.

The presence of invasive glioblastoma stem cells in glioblastoma (12) is thought to be the reason for poor survival prognosis. These cells contribute to recurrence and are highly resistant to typical treatments, which is partially due to the increased expression of the multidrug resistance of ATP-binding cassette transporter protein breakpoint cluster region pseudogene 1, DNA repair protein O-6-methylguanine-DNA methyltransferase and anti-apoptotic products in cluster of differentiation 133-expressing glioblastoma stem cells (13). This may explain, at least in part, why in the present study PCs are more sensitive to diisothiocyanate-derived mercapturic acids compared with SCs.

SCs exhibit increased therapy-resistance and are the reason for tumor recurrence (14); therefore, novel substances were sought which had been previously been identified to be selectively toxic to tumor cells. ITCs have been identified to exhibit a selective inhibitory capacity towards tumorigenesis (4). For instance, the ITC iberin induced apoptosis, inhibited tumor cell growth and was cytotoxic to the glioblastoma cell line SNB19 (15). Benzyl ITCs exhibited a decrease in proliferation, invasion and cell viability of U87 cells with an $\mathrm{EC}_{50}$ of $12.6 \mu \mathrm{M}(16)$, and a similar effect was identified by using the glioblastoma cell line GBM 8401 $\left(\mathrm{EC}_{50}, 6 \mu \mathrm{M}\right)(17,18)$. Furthermore, phenethyl ITC induced apoptosis in GBM 8401 cells at a final concentration of $8 \mu \mathrm{M}$ (19). In the present study, it was demonstrated that the recently identified diisothiocyanate-derived mercapturic acids (6) are selectively cytotoxic to the glioblastoma cell line $\mathrm{U} 87$ ( $\mathrm{EC}_{50}$ for $\left.\mathrm{J} 1,250 \mathrm{nM}\right)$, differentiated glioblastoma cells and glioblastoma stem cells at much lower concentrations compared with ITCs.

In a further set of experiments, it was investigated whether J1-J4 may lower the threshold of intrinsic TMZ resistance in SCs. To address this, J1, J2, J3 or J4 (at EC ${ }_{50}$ ) were co-cultured (3 days) with $0.6 \mu \mathrm{g} / \mathrm{ml}(3.09 \mu \mathrm{M}) \mathrm{TMZ}$ which represents the concentration in the brain following treatment with TMZ (20). No sensitizing effect of J1-J4 for TMZ-induced apoptosis was identified when TMZ was used at physiologically relevant concentrations (data not shown). Diisothiocyanate-derived mercapturic acids exert a more potent effect in comparison with TMZ, but do not exhibit a sensitizing effect for TMZ-mediated apoptosis.

The cell viability of PBMCs was not impaired by low concentrations of diisothiocyanate-derived mercapturic acids (Fig. 2), which is important since a chemopreventive mediator should activate an antitumor immune response and not inhibit the function of immune cells (21). Therefore, diisothiocyanate-derived mercapturic acids are potential therapeutic components to eliminate glioblastoma stem cells and may be considered for novel therapeutic treatments for glioblastoma.

\section{Acknowledgements}

K-MD and M-AW were partially supported by the Förderkreis für Tumor-und Leukämiekranke Kinder Ulm e.V., T.B. was supported by Alexander von Humboldt Polish Honorary Research Scholarship (grant no. DPK-422-1658/2013), and J.O. was supported by the National Science Center Poland (grant no. 2011/03/B/ST5/01058).

\section{References}

1. Jue TR and McDonald KL: The challenges associated with molecular targeted therapies for glioblastoma. J Neurooncol 127: 427-434, 2016.

2. Koukourakis MI, Mitrakas AG and Giatromanolaki A: Therapeutic interactions of autophagy with radiation and temozolomide in glioblastoma: Evidence and issues to resolve. Br J Cancer 114: 485-496, 2016.

3. Dinkova-Kostova AT and Kostov RV: Glucosinolates and isothiocyanates in health and disease. Trends Mol Med 18: 337-347, 2012.

4. Singh SV and Singh K: Cancer chemoprevention with dietary isothiocyanates mature for clinical translational research. Carcinogenesis 33: 1833-1842, 2012.

5. Trachootham D, Zhou Y, Zhang H, Demizu Y, Chen Z, Pelicano H, Chiao PJ, Achanta G, Arlinghaus RB, Liu J and Huang P: Selective killing of oncogenically transformed cells through a ROS-mediated mechanism by beta-phenylethyl isothiocyanate. Cancer Cell 10: 241-252, 2006. 
6. Grzywa R, Winiarski Ł, Psurski M, Rudnicka A, Wietrzyk J, Gajda T and Oleksyszyn J: Synthesis and biological activity of diisothiocyanate-derived mercapturic acids. Bioorg Med Chem Lett 26: 667-671, 2016.

7. Schneider M, Ströbele S, Nonnenmacher L, Siegelin MD Tepper M, Stroh S, Hasslacher S, Enzenmüller S, Strauss G, Baumann B, et al: A paired comparison between glioblastoma 'stem cells' and differentiated cells. Int J Cancer 138: 1709-1718, 2016.

8. Ströbele S, Schneider M, Schneele L, Siegelin MD, Nonnenmacher L, Zhou S, Karpel-Massler G, Westhoff MA, Halatsch ME and Debatin KM: A potential role for the inhibition of PI3K signaling in glioblastoma therapy. PLoS One 10: e0131670, 2015.

9. Westhoff MA, Zhou S, Bachem MG, Debatin KM and Fulda S: Identification of a novel switch in the dominant forms of cell adhesion-mediated drug resistance in glioblastoma cells. Oncogene 27: 5169-5181, 2008.

10. Cheng F, Li W, Zhou Y, Shen J, Wu Z, Liu G, Lee PW and Tang Y: admetSAR: A comprehensive source and free tool for evaluating chemical ADMET properties. J Chem Inf Model 52: 3099-3105, 2012

11. Schneider M, Ströbele S, Nonnenmacher L, Siegelin MD, Tepper M, Stroh S, Hasslacher S, Enzenmüller S, Strauss G, Baumann B, et al: A paired comparison between glioblastoma 'stem cells' and differentiated cells. Int J Cancer 138: 1709-1718, 2016.

12. Singh SK, Clarke ID, Terasaki M, Bonn VE, Hawkins C, Squire J and Dirks PB: Identification of a cancer stem cell in human brain tumors. Cancer Res 63: 5821-5828, 2003.

13. Liu G, Yuan X, Zeng Z, Tunici P, Ng H, Abdulkadir IR, Lu L, Irvin D, Black KL and Yu JS: Analysis of gene expression and chemoresistance of $\mathrm{CD}_{133^{+}}$cancer stem cells in glioblastoma. Mol Cancer 5: 67, 2006.
14. Jordan CT, Guzman ML and Noble M: Cancer stem cells. N Engl J Med 355: 1253-1261, 2006.

15. Jadhav U, Ezhilarasan R, Vaughn SF, Berhow MA and Mohanam S: Dietary isothiocyanate iberin inhibits growth and induces apoptosis in human glioblastoma cells. J Pharmacol Sci 103: 247-251, 2007.

16. Zhu Y, Liu A, Zhang X, Qi L, Zhang L, Xue J, Liu Y and Yang P: The effect of benzyl isothiocyanate and its computer-aided design derivants targeting alkylglycerone phosphate synthase on the inhibition of human glioma U87MG cell line. Tumour Biol 36: 3499-3509, 2015.

17. Tang NY, Chueh FS, Yu CC, Liao CL, Lin JJ, Hsia TC, Wu KC, Liu HC, Lu KW and Chung JG: Benzyl isothiocyanate alters the gene expression with cell cycle regulation and cell death in human brain glioblastoma GBM 8401 cells. Oncol Rep 35: 2089-2096, 2016.

18. Shang HS, Shih YL, Lu TJ, Lee CH, Hsueh SC, Chou YC, Lu HF, Liao NC and Chung JG: Benzyl isothiocyanate (BITC) induces apoptosis of GBM 8401 human brain glioblastoma multiforms cells via activation of caspase-8/bid and the reactive oxygen species-dependent mitochondrial pathway. Environmental Toxicology 31: 1751-1760, 2016.

19. Chou YC, Chang MY, Wang MJ, Harnod T, Hung CH, Lee HT, Shen CC and Chung JG: PEITC induces apoptosis of human brain glioblastoma GBM8401 cells through the extrinsic- and intrinsic -signaling pathways. Neurochem Int 81: 32-40, 2015.

20. Portnow J, Badie B, Chen M, Liu A, Blanchard S and Synold TW: The neuropharmacokinetics of temozolomide in patients with resectable brain tumors: Potential implications for the current approach to chemoradiation. Clin Cancer Res 15: 7092-7098, 2009.

21. Patel MA, Kim JE, Ruzevick J, Li G and Lim M: The future of glioblastoma therapy: Synergism of standard of care and immunotherapy. Cancers (Basel) 6: 1953-1985, 2014. 